Check for updates

Cite this: RSC Adv., 2021, 11, 18040

\title{
The graphite-catalyzed ipso-functionalization of arylboronic acids in an aqueous medium: metal- free access to phenols, anilines, nitroarenes, and haloarenes $\dagger$
}

\author{
Anshu Dandia, ${ }^{\text {a }}$ Ruchi Sharma, ${ }^{a}$ Pratibha Saini, ${ }^{a}$ Ranveer Singh Badgoti, \\ Kuldeep S. Rathore ${ }^{b}$ and Vijay Parewa (D) *a
}

\begin{abstract}
An efficient, metal-free, and sustainable strategy has been described for the ipso-functionalization of phenylboronic acids using air as an oxidant in an aqueous medium. A range of carbon materials has been tested as carbocatalysts. To our surprise, graphite was found to be the best catalyst in terms of the turnover frequency. A broad range of valuable substituted aromatic compounds, i.e., phenols, anilines, nitroarenes, and haloarenes, has been prepared via the functionalization of the $\mathrm{C}-\mathrm{B}$ bond into $\mathrm{C}-\mathrm{N}, \mathrm{C}-$ $\mathrm{O}$, and many other $\mathrm{C}-\mathrm{X}$ bonds. The vital role of the aromatic $\pi$-conjugation system of graphite in this protocol has been established and was observed via numerous analytic techniques. The heterogeneous nature of graphite facilitates the high recyclability of the carbocatalyst. This effective and easy system provides a multipurpose approach for the production of valuable substituted aromatic compounds without using any metals, ligands, bases, or harsh oxidants.
\end{abstract}

\begin{abstract}
Received 11th March 2021 Accepted 30th April 2021

DOI: $10.1039 / \mathrm{d} 1 \mathrm{ra0} 1940 f$

rsc.li/rsc-advances
\end{abstract}

hydroperoxide (TBHP), ozone, $\mathrm{PhI}(\mathrm{OAc})_{2}$, benzoquinone, or hydrogen peroxide $\left(\mathrm{H}_{2} \mathrm{O}_{2}\right)$, which can be explosive or have a hazardous environmental impact. These reactions can also entail high temperatures, strongly basic conditions, and the use of metal catalysts ( $\mathrm{Pd}, \mathrm{Au}, \mathrm{Cu}, \mathrm{Ru}, \mathrm{Ag}$, etc.) and microwave irradiation, and they often require the use of expensive specialized ligands. As phenols are susceptible to oxidants, the quantity of oxidant needs to be cautiously determined. Moreover, the removal of trace quantities of metal-containing catalysts from the final compounds can be complicated. Therefore, the development of sustainable protocols for the above transformation presents a difficult task for chemists.

To meet the requirements of green chemistry, carbon-based materials, such as ordered mesoporous carbon, activated carbon, graphene-based materials, graphite, and carbon nanotubes, open up opportunities in the field of catalysis due to their inimitable physical and chemical properties. ${ }^{10}$ In recent years, many scientists have established that carbon-based materials can show elevated catalytic efficiencies in organic synthesis compared to traditional metal catalysts. ${ }^{11}$ The sustainable nature of these carbon-based materials has been well documented in the literature. ${ }^{12}$ Among them, the use of graphite as an environmentally benign catalyst in organic synthesis has taken on vast significance. ${ }^{13}$

Continuing our interest in developing sustainable protocols for organic synthesis, ${ }^{\mathbf{1 4}}$ herein, we evaluate the catalytic activities of various carbon-based substances for the preparation of a library of phenol derivatives via the ipso-hydroxylation of 


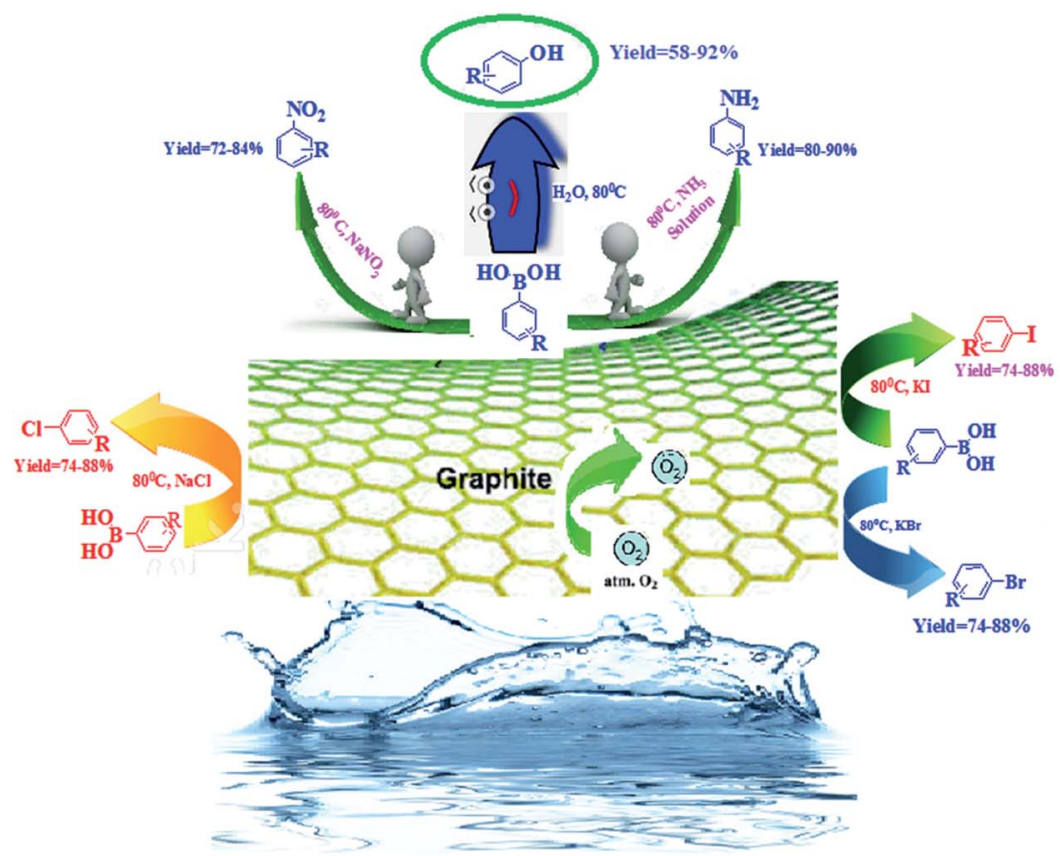

Scheme 1 The synthesis of substituted phenols, anilines, nitroarenes, and haloarenes from arylboronic acids.

arylboronic acid, utilizing water as an environmentally friendly solvent under sustainable conditions. Commercially available graphite was found to be the best metal-free carbocatalyst for the above transformation. Furthermore, we have also extended our strategy to the synthesis of anilines, nitroarenes, and haloarenes via transforming the $\mathrm{C}-\mathrm{B}$ bond of arylboronic acid to $\mathrm{C}-\mathrm{N}$ and many other $\mathrm{C}-\mathrm{X}$ bonds (Scheme 1 ).

\section{Results and discussion}

Firstly, phenylboronic acid has been selected as a model reactant for ipso-hydroxylation in an aqueous medium under air at $80^{\circ} \mathrm{C}$ (Table 1). No transformation of phenylboronic acid into phenol was noticed in the absence of catalyst. This outcome forced us to further optimize the reaction conditions. Recently, we have developed a series of carbon-based catalysts for various organic transformations. ${ }^{15}$ Therefore, from a sustainable point of view, the catalytic competences of various carbocatalysts have been studied. To our surprise, graphite was found to be the best catalyst for this transformation in terms of the turnover frequency $\left(\mathrm{TOF}^{15 b, 16}\right)$. Moreover, inferior yields were observed upon using other carbon-based materials as catalysts. GO and rGO gave poor product yields. Approximately similar catalytic activities were observed when the reaction was tried with various graphite samples purchased from different vendors.

An improvement in the yield of the desired product to an immense extent (36-92\%) was observed when the catalyst loading was increased from 5 to $20 \mathrm{wt} \%$ (Table 1 ). We have tried

Table 1 The catalytic competences of various carbocatalysts for the ipso-hydroxylation of phenylboronic acid ${ }^{a}$

\begin{tabular}{|c|c|c|c|c|c|}
\hline S. no. & Catalyst & Solvent & Time & Yield $^{b}(\%)$ & $\operatorname{TOF}\left(\times 10^{-3} \mathrm{~mol} \mathrm{~g}^{-1} \mathrm{~min}^{-1}\right)$ \\
\hline 1 & - & $\mathrm{H}_{2} \mathrm{O}$ & $24 \mathrm{~h}$ & - & n.c. \\
\hline 2 & Graphite $(20$ wt $\%)$ & $\mathrm{H}_{2} \mathrm{O}$ & $24 \mathrm{~h}$ & 92 & 0.021 \\
\hline 4 & MWCNTs $(20 \mathrm{wt} \%)^{c}$ & $\mathrm{H}_{2} \mathrm{O}$ & $24 \mathrm{~h}$ & 72 & 0.016 \\
\hline 5 & GO (20 wt\%) & $\mathrm{H}_{2} \mathrm{O}$ & $24 \mathrm{~h}$ & 21 & 0.005 \\
\hline 6 & rGO (20 wt $\%)$ & $\mathrm{H}_{2} \mathrm{O}$ & $24 \mathrm{~h}$ & 48 & 0.011 \\
\hline 9 & Graphite $(20 \mathrm{wt} \%)^{d}$ & $\mathrm{H}_{2} \mathrm{O}$ & $24 \mathrm{~h}$ & - & - \\
\hline 10 & Graphite (20 wt\%) & $\mathrm{CH}_{3} \mathrm{CN}$ & $24 \mathrm{~h}$ & 82 & 0.019 \\
\hline 11 & Graphite $(20$ wt\%) & $\mathrm{MeOH}$ & $24 \mathrm{~h}$ & 69 & 0.016 \\
\hline 12 & Graphite (20 wt\%) & THF & $24 \mathrm{~h}$ & 44 & 0.010 \\
\hline 13 & Graphite $(20$ wt $\%)$ & DMSO & $24 \mathrm{~h}$ & 38 & 0.009 \\
\hline
\end{tabular}

${ }_{d}^{a}$ Reactions were carried out with phenylboronic acid $(2 \mathrm{mmol})$ in $\mathrm{H}_{2} \mathrm{O}$ at $80{ }^{\circ} \mathrm{C}$ under air. ${ }^{b}$ Isolated yield. ${ }^{c}$ Multi-walled carbon nanotubes.

${ }^{d}$ Conversion conducted under a $\mathrm{N}_{2}$ atmosphere. 
different catalyst loadings $(20,30,40$, and $50 \mathrm{wt} \%)$, however further increases in catalyst loading did not affect the yield, and the optimum loading of catalyst was $20 \mathrm{wt} \%$. The desired product was not formed when the model reaction was conducted under a nitrogen atmosphere. These results show that, from a sustainable point of view, air is an effective and environmentally benign oxidant. The desirable transformation was not observed in the absence of graphite, which shows that graphite plays a vital role in the further activation of oxygen molecules from air for the catalytic reaction.

A series of trials was carried out using a variety of solvents. Methanol and acetonitrile were found to give moderate yields among the various organic solvents. Compared to conventional organic solvents, $\mathrm{H}_{2} \mathrm{O}$ was found to be a best solvent for the above transformation from an economical perspective. The outcome can be attributed to the excellent dispersion of the catalyst in $\mathrm{H}_{2} \mathrm{O}$. Additionally, the substrates show good dissolving capacities in water. The model reaction was also performed at different temperatures $\left(60{ }^{\circ} \mathrm{C}, 80{ }^{\circ} \mathrm{C}\right.$, and $\left.100{ }^{\circ} \mathrm{C}\right)$. It was concluded that, to achieve maximum conversion to the product, $80{ }^{\circ} \mathrm{C}$ was required.

To recognize the responsible catalytic sites in carbon-based catalysts, various organic compounds were employed as catalysts for the above transformation. Compounds with various oxygen functionalities showed poor catalytic activities. These outcomes confirmed that oxygen-containing functional groups may not be the catalytic sites in the carbon materials for hydroxylation. It was recognized from various catalytic tests that compounds containing aromatic $\pi$-conjugation systems demonstrated reasonable catalytic activities (Table 2). We suppose that the aromatic $\pi$-conjugation system has intrinsic activity for the above transformation. Thus, carbon materials that have significant oxygen functionality showed poor results compared to graphite.

Carbon materials illustrate metallic features and activate $\mathrm{O}_{2}$ due to the presence of delocalized $\pi$-electrons. ${ }^{17}$ The introduction of any surface defects into a carbon material decreases its catalytic activity because this diminishes the mobility of delocalized $\pi$-electrons. ${ }^{18}$ Activated charcoal showed lower catalytic activity due to its decreased mass transfer efficiency because of its high degree of defects and its microporous structure. ${ }^{19}$ It has been revealed in the literature that $\mathrm{sp}^{2}$-hybridized carbon atoms are vital centers for oxygen adsorption and activation. ${ }^{17}$ These activated oxygen atoms can move on graphitic planes. As we already showed the necessity of oxygen for the above transformation, we proposed that the activation of oxygen was a decisive step in this transformation. The graphitic planes of the catalyst transform atmospheric $\mathrm{O}_{2}$ to short-lived $\mathrm{O}_{2}{ }^{--}$ species that are stored in the carbon pores. ${ }^{17}$

There is a possibility that the observed catalytic properties of graphite could be attributed to the presence of trace metal-ion impurities. To establish the presence of trace amounts of metal ions, we have studied graphite catalyst samples (fresh and reused) via various analytical techniques. EDAX analysis confirmed the absence of any transition metals in the graphite catalyst, which ruled out catalytic assistance from any metal impurities. Moreover, the carbon : oxygen atomic ratios of fresh
Table 2 The catalytic activities of various organic counterparts ${ }^{a}$

(2) no.

\footnotetext{
${ }^{a}$ Reactions were carried out with phenylboronic acid (2 mmol) in $\mathrm{H}_{2} \mathrm{O}$ at $80{ }^{\circ} \mathrm{C}$ under air. ${ }^{b}$ Isolated yield.
}

and reused graphite were comparable, showing the stable nature of the graphite catalyst during the reaction (see ESI, Fig. S1 and S2 $\dagger$ ).

The deconvoluted C 1s XPS spectrum of fresh graphite shows a peak at $284.4 \mathrm{eV}$. Additionally, the $\mathrm{O} 1 \mathrm{~s}$ spectrum illustrates a broad peak from 530 to $535 \mathrm{eV}$. The intensities and energies of the peaks of reused graphite in both XPS spectra were approximately the same (Fig. 1).

In the Fourier-transform infrared (FT-IR) spectrum of reused graphite, absorption peak fluctuations from 1443 to $1573 \mathrm{~cm}^{-1}$ are noted because of aromatic $\mathrm{C}=\mathrm{C}$ stretching (Fig. 2a). We have also carried out solid-state ${ }^{13} \mathrm{C}$-NMR spectroscopy analysis of reused graphite (see ESI, Fig. S5 $\dagger$ ). The spectrum showed broad resonance associated with $\mathrm{sp}^{2}$-hybridized carbon atoms. ${ }^{20}$ There were no additional peaks from any oxygen functionalities in the FT-IR and solid-state ${ }^{13} \mathrm{C}$-NMR spectra of reused graphite. 

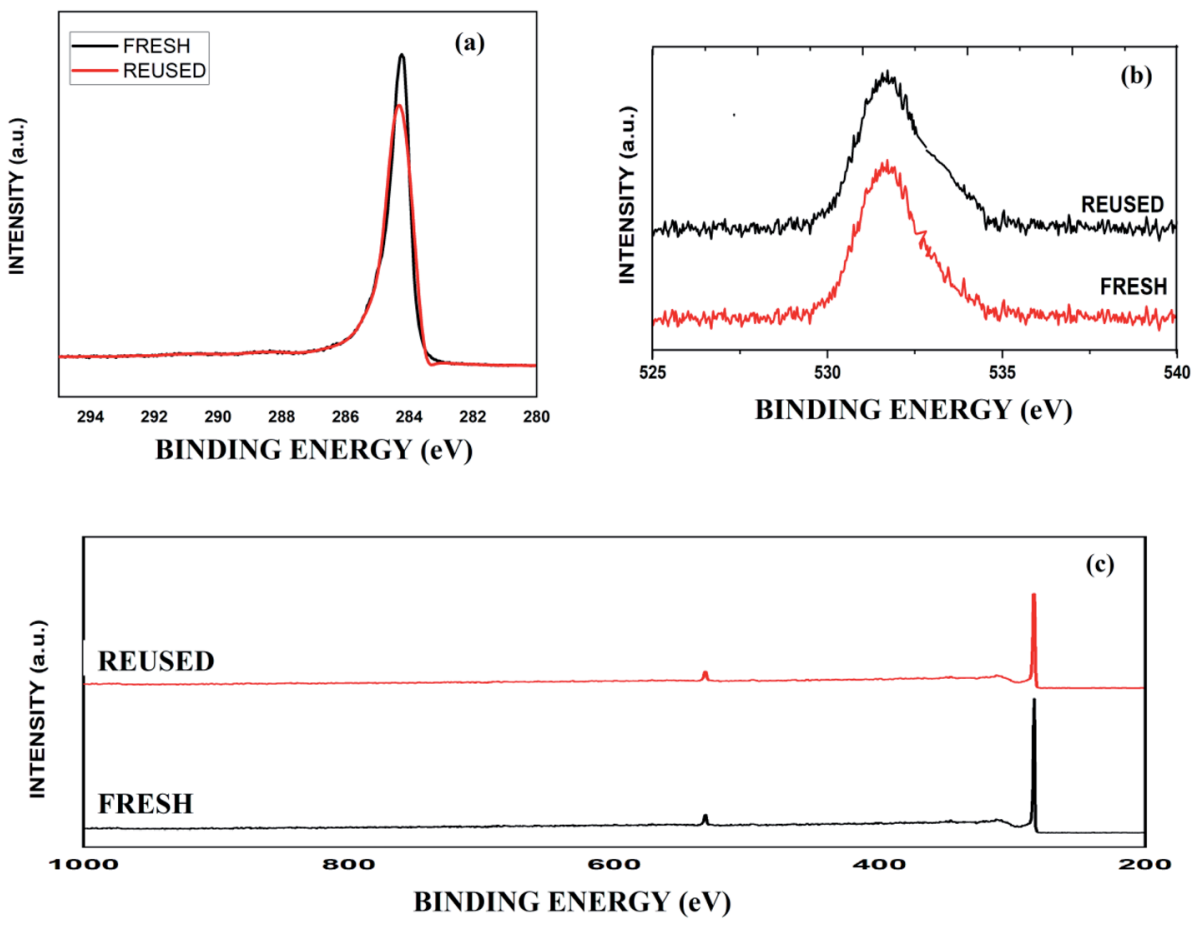

Fig. 1 The XPS spectra of fresh and reused graphite: (a) C 1s spectra; (b) O 1s spectra; and (c) the complete XPS spectra.
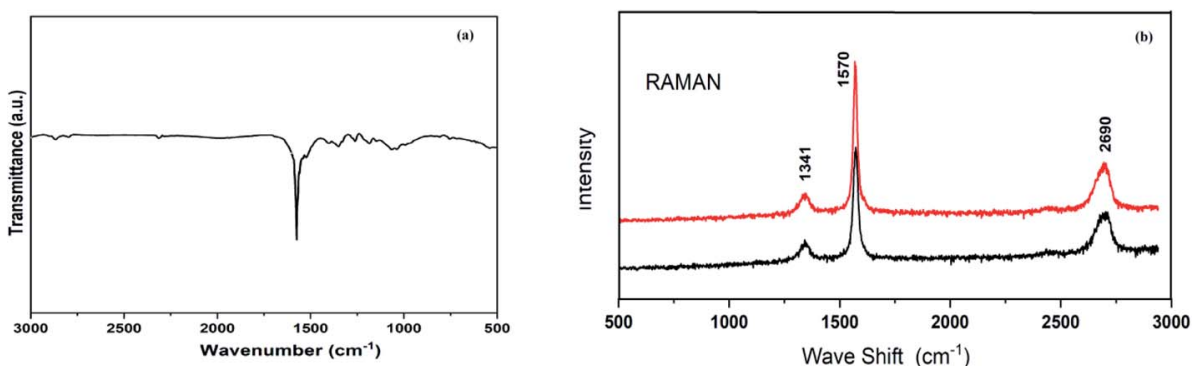

Fig. 2 (a) The FT-IR spectrum of reused graphite and (b) Raman spectra of fresh and reused graphite.

The Raman spectra of fresh and reused catalyst graphite samples comprise many overlapping bands (Fig. 2b). The D band, G band, and 2D band arise at around $1341 \mathrm{~cm}^{-1}$, $1570 \mathrm{~cm}^{-1}$, and $2690 \mathrm{~cm}^{-1}$, respectively.

In SEM images, the graphite sheets displayed crumpled and wrinkled surfaces of thin lamellae (Fig. 3a, see ESI, Fig. S3†). The average particle size of the catalyst is about $9.8 \mu \mathrm{m}$. The morphology and average particle size of the reused catalyst remain unchanged, as shown by SEM images of the reused graphite catalyst after four runs. The XRD pattern of recycled graphite was similarly documented, indicating that the structural integrity remains unchanged after the transformation reaction (Fig. 3b).

These analytical results proved that no oxidation of the catalyst was observed during the reaction, and the aromatic nature of the catalyst remains constant throughout the process. These results demonstrate that the utilized graphite catalyst is a stable and reusable catalyst for the above transformation.
To further confirm the role of the catalyst in the activation of the oxygen, EPR measurements were carried out with DMPO (see ESI, Fig. S5 $\dagger$ ). When the EPR experiment was performed with catalyst, peaks from the spin adduct of the DMPO superoxide radical were observed, ${ }^{21}$ while in the absence of catalyst, these peaks were absent. This result indicated that the generation of superoxide radicals was indispensable for the reaction to proceed.

These results suggest that a radical process might be involved in the above transformation. We also conducted the reaction with $\mathrm{H}_{2} \mathrm{O}^{18}$ as a solvent under optimized conditions. The incorporation of ${ }^{18} \mathrm{O}$ into the product was not viewed, which ruled out the possibility of water acting as an oxygen source (Scheme 2).

In most cases, literature reports reveal the requirement for a base/metal in the reaction when phenylboronic acid reacts with reactive oxygen species. ${ }^{22}$ The mechanism of the reaction is ambiguous, particularly in light of the fact that the reaction can 

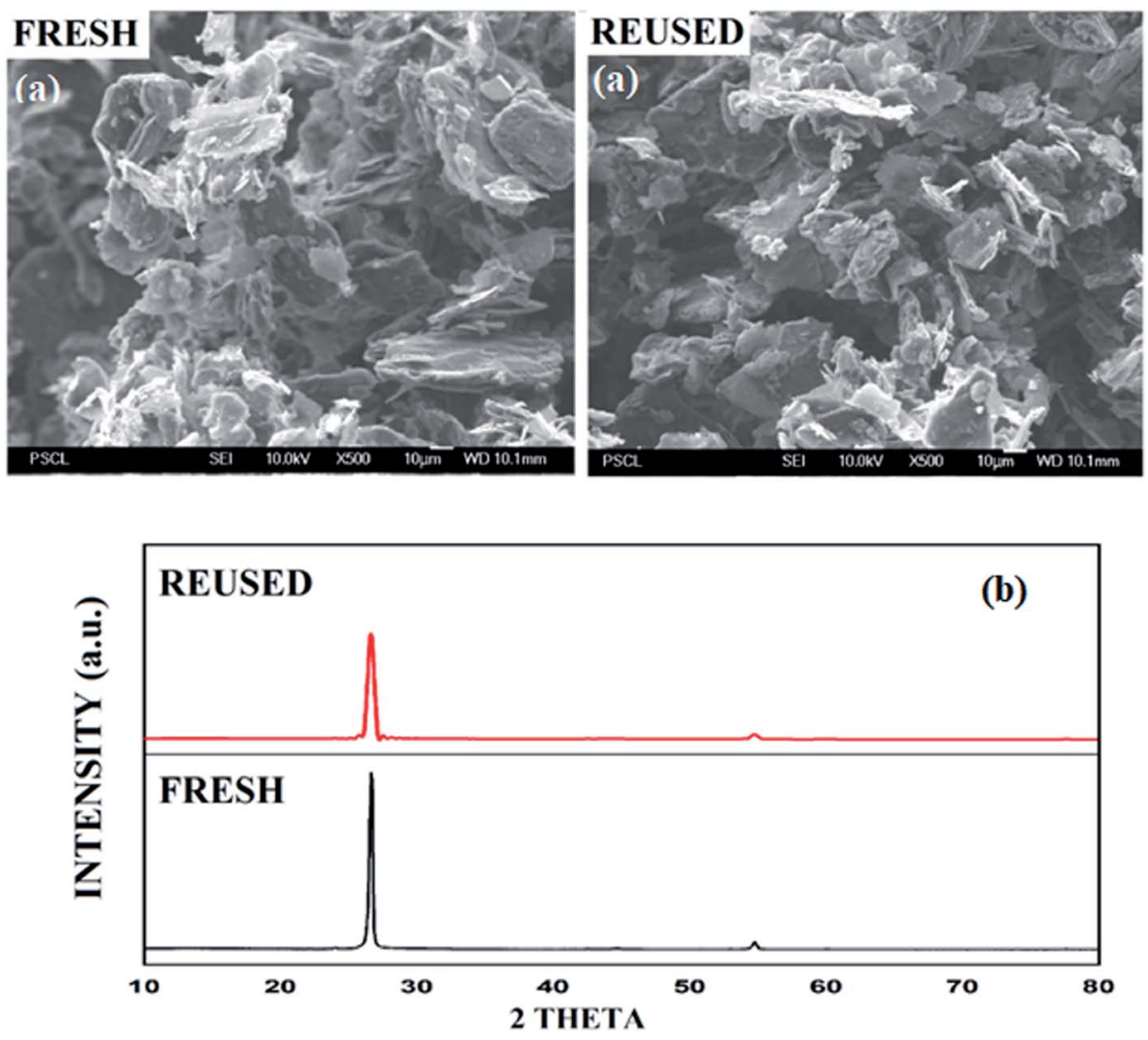

Fig. 3 (a) SEM images and (b) XRD patterns of fresh and reused graphite.<smiles>OB(O)c1ccccc1</smiles><smiles>CCCCC</smiles><smiles>[18OH]</smiles><smiles>Cc1ccccc1</smiles>

$2 a^{18} \mathrm{O}$ Not observed

Scheme 2 Isotopic experiment results.

occur in the absence of any base/metal under air. Via control experiments, we have already confirmed that a radical process might be involved in the transformation. Due to the presence of delocalized $\pi$-electrons, graphitic planes convert $\mathrm{O}_{2}$ to shortlived $\mathrm{O}_{2}{ }^{-}$species that assemble in the carbon pores. ${ }^{17}$ This short-lived $\mathrm{O}_{2}{ }^{\cdot-}$ was the active sustainable oxidant for the above transformation. Based on the above information and literature reports, ${ }^{23}$ we considered that the reaction occurred via a radical nucleophilic substitution mechanism ${ }^{24}$ through an unexplored process (to be the subject of future investigations). Owing to the presence of a delocalized $\pi$-electron system, graphite also stabilizes the radical intermediates for better reaction performance.

To elaborate on the possibilities of this approach, numerous electronically diversified phenylboronic acids were used for hydroxylation under the established optimum conditions (Table 3). This approach shows broad functional-group tolerance. Arylboronic acids containing electron-withdrawing and -donating substituents at the para position gave excellent phenol yields. The use of sterically demanding orthosubstituted arylboronic acids did not influence the yields drastically, and the final products were achieved in good yields. meta-Substituted arylboronic acids gave analogous outcomes. Heteroaryl boronic acids also gave good yields in the optimized reaction environment.

Encouraged by the above results, we would like to examine whether the formation of anilines would happen when aqueous $\mathrm{NH}_{3}$ solution was inserted into the system due to nucleophilic competition between the nitrogen and oxygen centers. To our delight, the formation of aniline was observed instead of phenol. A probable reason for this is that the superior nucleophilic power of the nitrogen center compared to the oxygen center led to the construction of aniline instead of phenol (Scheme 3). Therefore, the reaction proceeds through the more nucleophilic center (in this case the nitrogen center) instead of the oxygen center. Similarly, when we added $\mathrm{NaNO}_{2}$ to the system instead of aqueous $\mathrm{NH}_{3}$, nitroarenes were formed.

Inspired by these outcomes, we used the same sustainable protocol for the iodination of arylboronic acids, using KI as an iodide source. As iodide ions have more nucleophilic power, iodobenzene was formed as the sole product. In the same way, when we used $\mathrm{KBr}$ in the system, bromobenzene was formed as the desired product. Unfortunately, $\mathrm{KCl}$ failed to give the halogenated product under these conditions. However, $\mathrm{NaCl}$ withstands the reaction conditions and gives the chlorinated 
Table 3 The graphite-catalyzed ipso-hydroxylation of arylboronic acids ${ }^{a}$

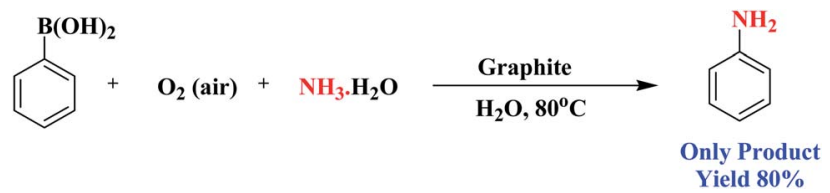

Scheme 3 Intermolecular competition between the oxygen and nitrogen centres during the functionalization of phenylboronic acid.

product in good yield. Since the functionalization of phenylboronic acids at the nitrogen center was successful in the presence of an oxygen center, a competitive trial was executed to determine which phenylboronic acid functionalization would happen when three halogen reactants were added at the same time (Scheme 4). Under these conditions, iodobenzene was formed as a major product, with the order $\mathrm{I}>\mathrm{Br}>\mathrm{Cl}$.
This protocol gave excellent outcomes when using $\mathrm{NH}_{3} \cdot \mathrm{H}_{2} \mathrm{O}$, $\mathrm{NaNO}_{2}, \mathrm{KI}, \mathrm{KBr}$, and $\mathrm{NaCl}$ as the functional-group sources. 1.5 eq. of these reagents was adequate for the reaction and the addition of additional amounts did not affect the yields remarkably. It was found that a temperature of $80{ }^{\circ} \mathrm{C}$ with a loading of $10 \mathrm{wt} \%$ catalyst was appropriate to give quantitative amounts of anilines, nitroarenes, and haloarenes. We employed our established conditions with the model substrates described in Scheme 5. The formation of anilines, nitroarenes, and haloarenes was not identified in the absence of atmospheric air (under a $\mathrm{N}_{2}$ environment), and the outcome designated that an oxidative route was involved in the synthesis of these useful compounds. To demonstrate the opportunity and boundaries of the above approach, we used a broad range of arylboronic acids. The reactions proceeded efficiently with electron-withdrawing<smiles>Clc1ccccc1</smiles>

Scheme 4 Intermolecular competition between various halide centres during the functionalization of phenylboronic acid. 


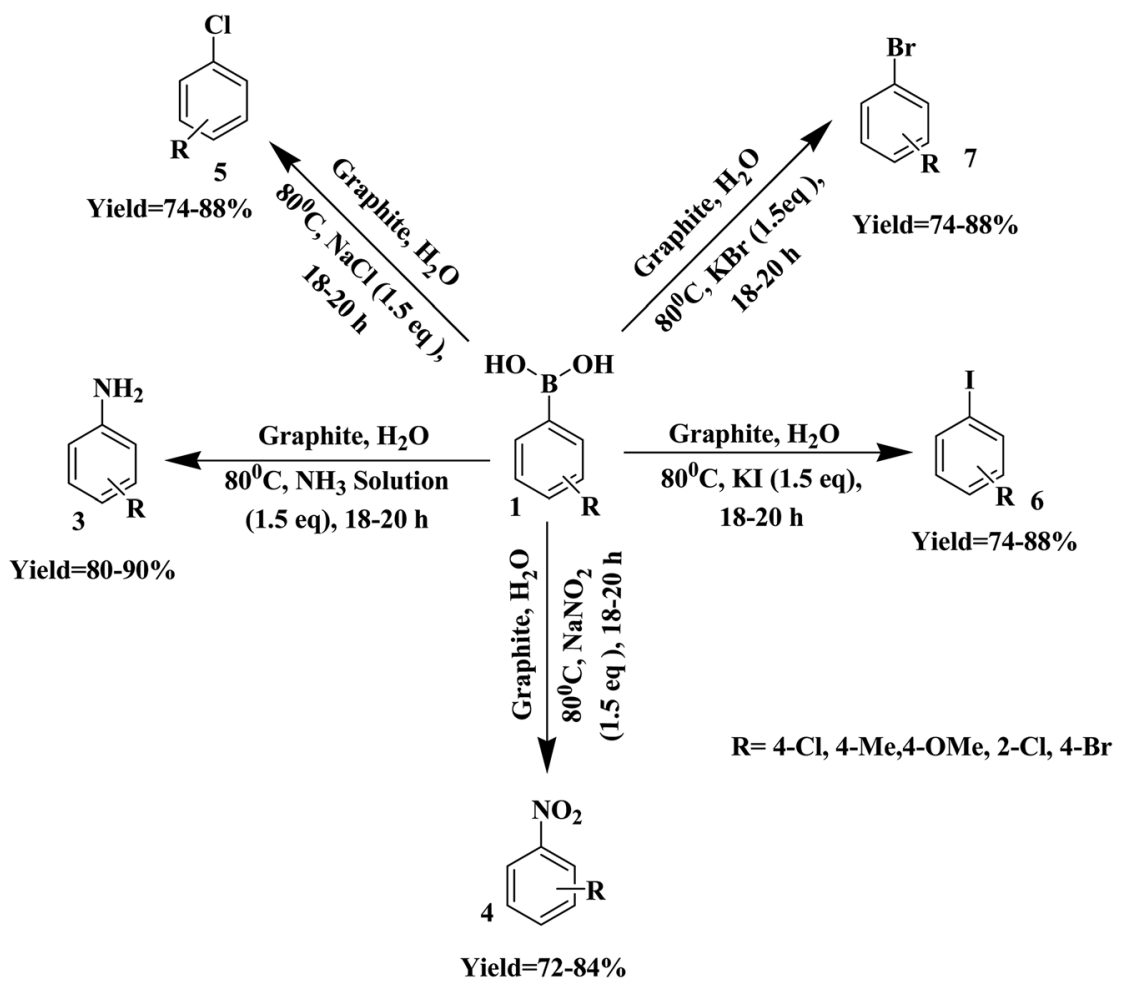

Scheme 5 The synthesis of substituted anilines, nitroarenes, and haloarenes from arylboronic acids.

and electron-donating arylboronic acids, but lower and more variable yields were obtained in the case of chlorobenzenes.

The heterogeneous character and excellent recyclability of graphite was confirmed (see ESI $\dagger$ ). For recycling experiments, arylboronic acid was selected as the model substrate for all transformations. The used graphite was simply isolated via filtration, cleaned with ethanol, and reused for an additional four cycles. As shown in Table 4, graphite was found to be a very stable carbocatalyst for all these transformations.

\section{Experimental}

\subsection{General}

See ESI.†

\subsection{Preparation of substituted phenols (2)}

A round-bottomed flask was loaded with arylboronic acid (2 mmol) and $20 \mathrm{wt} \%$ graphite in $20 \mathrm{~mL}$ of $\mathrm{H}_{2} \mathrm{O}$, and the mixture was stirred at $80^{\circ} \mathrm{C}$ until complete transformation was achieved

Table 4 Recyclability experiments involving graphite for various functional group transformations ${ }^{a}$

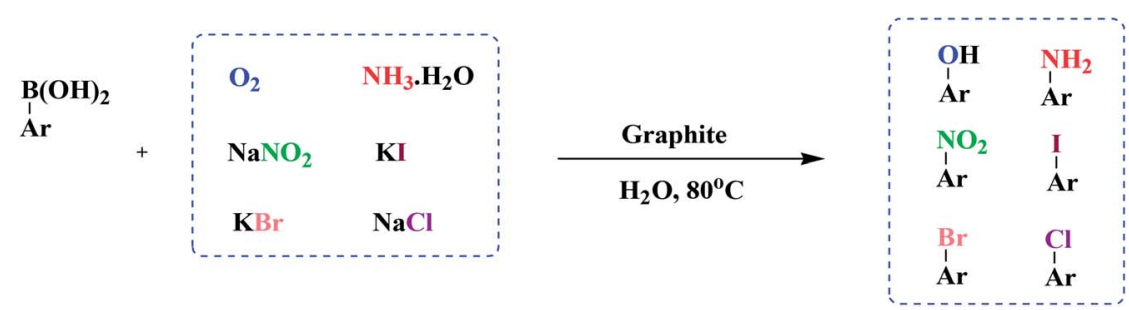

\begin{tabular}{lllll}
\hline $\begin{array}{l}\text { Functional } \\
\text { entity }\end{array}$ & $\begin{array}{l}\text { First cycle } \\
{[\%]}\end{array}$ & $\begin{array}{l}\text { Second cycle } \\
{[\%]}\end{array}$ & $\begin{array}{l}\text { Third cycle } \\
{[\%]}\end{array}$ \\
\hline $\mathrm{Ph}-\mathrm{OH}$ & 92 & 88 & 86 & 86 \\
$\mathrm{Ph}-\mathrm{NH}_{2}$ & 80 & 78 & 77 & 77 \\
$\mathrm{Ph}-\mathrm{NO}_{2}$ & 72 & 70 & 68 & 68 \\
$\mathrm{Ph}-\mathrm{I}$ & 76 & 72 & 72 & 71 \\
$\mathrm{Ph}-\mathrm{Br}$ & 73 & 71 & 71 & 68 \\
$\mathrm{Ph}-\mathrm{Cl}$ & 72 & 67 & 66 & 66
\end{tabular}

${ }^{a}$ Isolated product yield. 
(checked via TLC). The used graphite was removed simply via filtration after the transformation was complete. The filtrate was permitted to cool to atmospheric temperature and was then extracted with ethyl acetate $(3 \times 2 \mathrm{~mL})$. The solution was then concentrated under reduced pressure and purified via column chromatography on silica gel (eluent, hexane : EtOAc) to furnish the pure final product.

\subsection{Preparation of substituted anilines (3)}

A round-bottomed flask was loaded with arylboronic acid (2 $\mathrm{mmol}$ ), $\mathrm{NH}_{3}$ solution (1.5 eq.) and $20 \mathrm{wt} \%$ graphite in $20 \mathrm{~mL}$ of $\mathrm{H}_{2} \mathrm{O}$, and the mixture was stirred at $80{ }^{\circ} \mathrm{C}$ until the complete transformation was achieved (checked via TLC). The used graphite catalyst was separated simply via filtration after the completion of the transformation. The filtrate was permitted to cool to atmospheric temperature and was then extracted with ethyl acetate $(3 \times 2 \mathrm{~mL})$. The solution was then concentrated under reduced pressure and purified via column chromatography on silica gel (eluent, hexane : EtOAc) to deliver the required pure product.

\subsection{Preparation of substituted nitroarenes (4)}

A round-bottomed flask was loaded with arylboronic acid (2 mmol), $\mathrm{NaNO}_{2}$ (1.5 eq.) and $20 \mathrm{wt} \%$ graphite in $20 \mathrm{~mL}$ of $\mathrm{H}_{2} \mathrm{O}$, and the mixture was stirred at $80{ }^{\circ} \mathrm{C}$ until the conversion was complete (monitored via TLC). The used graphite was separated simply via filtration after the completion of the transformation. The filtrate was permitted to cool to atmospheric temperature and was then extracted with ethyl acetate $(3 \times 2 \mathrm{~mL})$. The solution was then concentrated under reduced pressure and purified via column chromatography on silica gel (eluent, hexane : EtOAc) to supply the final pure product.

\subsection{Preparation of substituted haloarenes (5-7)}

A round-bottomed flask was loaded with arylboronic acid (2 $\mathrm{mmol}), \mathrm{KCl}(1.5$ eq.)/KI (1.5 eq.)/KBr (1.5 eq.), and $20 \mathrm{wt} \%$ graphite in $20 \mathrm{~mL}$ of $\mathrm{H}_{2} \mathrm{O}$, and the mixture was stirred at $80{ }^{\circ} \mathrm{C}$ until complete transformation was achieved (checked via TLC). Graphite was isolated simply via filtration after the transformation was complete. The filtrate was permitted to cool to atmospheric temperature and was then extracted with ethyl acetate $(3 \times 2 \mathrm{~mL})$. The solution was then concentrated under reduced pressure and purified via column chromatography on silica gel (eluent, hexane : EtOAc) to offer the desired pure product.

\section{Conclusions}

A versatile and simple graphite-catalyzed process has been illustrated for the conversion of numerous functional groups on aromatic rings in an aqueous medium under air via the ipsofunctionalization of phenylboronic acids. Various important aromatic compounds, e.g., phenols, anilines, nitroarenes, and haloarenes, have been synthesized without using any metals, ligands, bases, or oxidants. The vital role of the aromatic $\pi$ conjugation system of graphite in assisting the reaction has been confirmed via various analytic techniques, viz., FT-IR, Raman, XPS, SEM, and XRD analysis. Via control experiments, we have offered a plausible mechanistic pathway for the above transformation. The main advantage of this protocol is the use of economical and abundant graphite as an efficient carbocatalyst without any prior treatment. Overall, this strategy offers numerous advantages, such as the recyclability of the catalyst, operational simplicity, inexpensiveness, environmental friendliness, a broad substrate scope, and high yields.

\section{Conflicts of interest}

There are no conflicts to declare.

\section{Acknowledgements}

DST-SERB, C.S.I.R., and U.G.C., New Delhi, are acknowledged for financial assistance. The authors are thankful to MNIT, Jaipur, for assistance with the spectral studies.

\section{References}

1 D. Hall, Boronic Acids: Preparation and Applications in Organic Synthesis, Medicine and Materials, ed. D. G. Hall, Wiley-VCH, Weinheim, 2nd edn, 2011.

2 (a) C. Kleeberg, L. Dang, Z. Lin and T. B. Marder, Angew. Chem., 2009, 121, 5454-5458; (b) M. Murata, T. Oyama, S. Watanabe and Y. Masuda, J. Org. Chem., 2000, 65, 164168; (c) W. Zhu and D. Ma, Org. Lett., 2006, 8, 261-263; (d) D. A. Wilson, C. J. Wilson, B. M. Rosen and V. Percec, Org. Lett., 2008, 10, 4879-4882; (e) F. Mo, Y. Jiang, D. Qiu, Y. Zhang and J. Wang, Angew. Chem., 2010, 49, 1846-1849; (f) J. Y. Cho, M. K. Tse, D. Holmes, R. E. Maleczka and M. R. Smith, Science, 2002, 295, 305-308; $(g)$ T. Ishiyama, J. Takagi, K. Ishida, N. Miyaura and N. R. Anastasi, Science, 2002, 295, 305-308; (h) T. Ishiyama, J. Takagi, K. Ishida, N. Miyaura, N. R. Anastasi and J. F. Hartwig, J. Am. Chem. Soc., 2002, 124, 390-391; (i) I. A. I. Mkhalid, J. H. Barnard, T. B. Marder, J. M. Murphy and J. F. Hartwig, Chem. Rev., 2010, 110, 890-931.

3 C. Zhua and R. F. John, Adv. Synth. Catal., 2014, 356, 23952410 .

4 (a) J. H. P. Tyman, Synthetic and Natural Phenols, Elsevier, New York, 1996; (b) Z. Rappoport, The Chemistry of Phenols, Wiley-VCH, Weinheim, Germany, 2003.

5 (a) R. W. Owen, A. Giacosa, R. Haubner, B. Spiegel-Hader and H. Bartsch, Eur. J. Cancer., 2000, 36, 1235-1247; (b) L. Pilato, React. Funct. Polym., 2013, 73, 270-277.

6 (a) C. Hoarau and T. R. R. Pettus, Synlett, 2003, 1, 127-137; (b) P. Hanson, J. R. Jones, A. B. Taylor, P. H. Walton and A. W. Timms, J. Am. Chem. Soc., 2002, 2, 1135-1150; (c) T. George, R. Mabon, G. Sweeney, J. B. Sweeney and A. Tavassoli, J. Am. Chem. Soc., 2000, 1, 2529-2574; (d) T. Schulz, C. Torborg and B. Schaffner, Angew. Chem., Int. Ed., 2009, 48, 918-921; (e) K. W. Anderson, T. Ikawa, R. E. Tundel and S. L. Buchwald, J. Am. Chem. Soc., 2006, 128, 10694-10695. 
7 (a) B. A. Dar, P. Bhatti, A. P. Singh, A. Lazar, P. R. Sharma, M. Sharma and B. Singh, Appl. Catal., A, 2013, 466, 60-67; (b) D. Yang, B. An, W. Wei, M. Jiang, J. You and H. Wang, Tetrahedron, 2014, 70, 3630-3634; (c) H. Yang, Y. Li, M. Jiang, J. Wang and H. Fu, Chem.-Eur. J., 2011, 17, 56525660; (d) A. Affrose, I. A. Azath, A. Dhakshinamoorthy and K. Pitchumani, J. Mol. Catal. A: Chem., 2014, 395, 500-505; (e) J. Xu, X. Wang, C. Shao, D. Su, G. Cheng and Y. Hu, Org. Lett., 2010, 12, 1964-1967; (f) K. Inamoto, K. Nozawa, M. Yonemoto and Y. Kondo, Chem. Commun., 2011, 47, 11775-11777; (g) A. D. Chowdhury, S. M. Mobin, S. Mukherjee, S. Bhaduri and G. K. Lahiri, Eur. J. Inorg. Chem., 2011, 21, 3232-3239; (h) J. Zheng, S. Lin, X. Zhu, B. Jiang, Z. Yang and Z. Pan, Chem. Commun., 2012, 48, 6235-6237; ( $i$ ) L. Wang, W. Zhang, D. Sheng Su, X. Meng and F.-S. Xiao, Chem. Commun., 2012, 48, 5476-5478; (j) N. Gogoi, P. K. Gogoi, G. Borah and U. Bora, Tetrahedron Lett., 2016, 57, 4050-4052; (k) T. Begum, A. Gogoi, P. K. Gogoi and U. Bora, Tetrahedron Lett., 2015, 56, 95-97; (l) T. Toyao, N. Ueno, K. Miyahara, Y. Matsui, T.-H. Kim, Y. Horiuchi, H. Ikeda and M. Matsuoka, Chem. Commun., 2015, 51, 16103-16106; ( $m$ ) M.-J. Zhang, H.-X. Li, H.-Y. Li and J.-P. Lang, Dalton Trans., 2016, 45, 17759-17769.

8 (a) G. K. S. Prakash, S. Chacko, C. Panja, T. E. Thomas, L. Gurung, G. Rasul, T. Mathew and G. A. Olah, Adv. Synth. Catal., 2009, 351, 1567-1574; (b) L. Wang, D.-Y. Dai, Q. Chen and M.-Y. He, J. Fluorine Chem., 2014, 158, 44-47; (c) S. Gupta, P. Chaudhary, V. Srivastava and J. Kandasamy, Tetrahedron Lett., 2016, 57, 2506-2510; (d) S. Guo, L. Lu and H. Cai, Synlett, 2013, 24, 1712-1714; (e) D.-S. Chen and J.-M. Huang, Synlett, 2013, 24, 499-501; (f) K. S. Webb and D. Levy, Tetrahedron Lett., 1995, 36, 5117-5118; $(g)$ B. R. Travis, B. P. Ciaramitaro and B. Borhan, Eur. J. Org. Chem., 2002, 2002, 3429-3434; (h) R. E. Maleczka Jr, F. Shi, D. Holmes and M. R. Smith III, J. Am. Chem. Soc., 2003, 125, 7792-7793; (i) G. A. Molander and L. N. Cavalcanti, J. Org. Chem., 2011, 76, 623-630; (j) E. Kianmehr, M. Yahyaee and K. Tabatabai, Tetrahedron Lett., 2007, 48, 2713-2715; (k) C. Zhu, R. Wang and J. R. Falck, Org. Lett., 2012, 14, 3494-3497; (l) Y. K. Bommegowda, N. Mallesha, A. C. Vinayaka and M. P. Sadashiva, Chem. Lett., 2016, 45, 268-270; $(m)$ K. Murugan and S. Palaniswamy, ACS Sustainable Chem. Eng., 2019, 7, 9028-9034.

9 (a) A. Paul, D. Chatterjee, H. T. Rajkamal, S. Banerjee and S. Yadav, Tetrahedron Lett., 2015, 56, 2496-2499; (b) N. Chatterjee, H. Chowdhury, K. Sneh and A. Goswami, Tetrahedron Lett., 2015, 56, 172-174; (c) J. S. Ruso, N. Rajendiran and R. S. Kumaran, Tetrahedron Lett., 2014, 55, 2345-2347; (d) G. Cheng, X. Zeng and X. Cui, Synthesis, 2014, 46, 295-300; (e) P. Gogoi, P. Bezboruah, J. Gogoi and R. C. Boruah, Eur. J. Org. Chem., 2013, 32, 7291-7294; (f) K. Hosoi, Y. Kuriyama, S. Inagi and T. Fuchigami, Chem. Commun., 2010, 46, 1284-1286; (g) H.-L. Qi, D.-S. Chen, J.-S. Ye and J.-M. Huang, J. Org. Chem., 2013, 78, 74827487; (h) H. Jiang, L. Lykke, S. U. Pedersen, W.-J. Xiao and K. A. Jørgensen, Chem. Commun., 2012, 48, 7203-7205; (i) A. N. Cammidge, V. H. M. Goddard, C. P. J. Schubert,
H. Gopee, D. L. Hughes and D. Gonzalez-Lucas, Org. Lett., 2011, 13, 6034-6037; (j) H. Kotoučová, I. Strnadová, M. Kovandová, J. Chudoba, H. Dvořáková and R. Cibulka, Org. Biomol. Chem., 2014, 12, 2137-2142; (k) X. Yu and S. M. Cohen, Chem. Commun., 2015, 51, 9880-9883; $(l)$ J. Luo, X. Zhang and J. Zhang, ACS Catal., 2015, 5, 22502254; $(m)$ S. P. Pitre, C. D. McTiernan, H. Ismaili and J. C. Scaiano, J. Am. Chem. Soc., 2013, 135, 13286-13289; (n) Y.-Q. Zou, J.-R. Chen, X.-P. Liu, L.-Q. Lu, R. L. Davis, K. A. Jørgensen and W.-J. Xiao, Angew. Chem., Int. Ed., 2012, 124, 802-812; (o) J. A. Johnson, J. Luo, X. Zhang, Y.-S. Chen, M. D. Morton, E. Echeverría, F. E. Torres and J. Zhang, ACS Catal., 2015, 5, 5283-5291; (p) W. Yina, X. Pana, W. Lenga, J. Chenb and H. Hec, Green Chem., 2019, 21, 4614-4618.

10 (a) L. Xien and L. Dai, Nat. Rev. Mater., 2016, 1, 1-12; (b) E. Pérez-Mayoral, V. Calvino-Casildaa and E. Soriano, Catal. Sci. Technol., 2016, 6, 1265-1291; (c) E. Lam and H. T. John Luong, ACS Catal., 2014, 4, 3393-3410.

11 (a) M. B. Gawande, P. Fornasiero and R. Zbořil, ACS Catal., 2020, 10, 2231-2259; (b) Z. Liu, B. Zhang, H. Yu, K. H. Wu and X. Huang, Front. Chem., 2020, 8, 308.

12 (a) K. P. Gopinath, D. V. N. Vo, D. G. Prakash, A. A. Joseph, S. Viswanathan and J. Arun, Environ. Chem. Lett., 2020, 126; (b) D. R. Dreyer and C. W. Bielawski, Chem. Sci., 2011, 2, 1233-1240; (c) S. S. Shang and G. Shuang, ChemCatChem, 2019, 11, 3730-3744; (d) S. Chenliang and K. P. Loh, Acc. Chem. Res., 2013, 46, 2275-2285.

13 (a) M. Nagai, R. Isoe, K. Ishiguro, H. Tominaga and M. Shimizu, Chem. Eng. J., 2012, 207, 938-942; (b) B. H. Han, D. H. Shin and S. Y. Cho, Tetrahedron Lett., 1985, 26, 6233-6234; (c) H. K. Kadam, S. Khan, R. A. Kunkalkar and S. G. Tilve, Tetrahedron Lett., 2013, 54, 1003-1007; (d) M. Kodomari, Y. Suzuki and K. Yoshida, Chem. Commun., 1997, 1567-1568; (e) M. R. Acocella, L. D'Urso, M. Maggio and G. Guerra, ChemCatChem, 2016, 8, 1915-1920; (f) K. N. Nandeesh, G. M. Raghavendra, C. N. Revanna, T. A. J. Vijay, K. S. Rangappa and K. Mantelingu, Synth. Commun., 2014, 44, 1103-1110.

14 (a) A. Dandia, V. Parewa, A. K. Jain and K. S. Rathore, Green Chem., 2011, 13, 2135-2145; (b) A. Dandia, V. Parewa, S. Kumari, S. Bansal and A. Sharma, Green Chem., 2016, 18, 2488-2499; (c) A. Dandia, S. L. Gupta, A. Indora, P. Saini, V. Parewa and K. S. Rathore, Tetrahedron Lett., 2017, 58, 1170-1175; (d) A. Dandia, S. Bansal, R. Sharma, D. K. Mahawar, K. S. Rathore, M. L. Meena and V. Parewa, J. Photochem. Photobiol., A, 2020, 389, 112242; (e) A. Dandia, S. Khan, R. Sharma, S. Parihar and V. Parewa, ChemistrySelect, 2017, 2, 9684-9690; (f) A. Dandia, S. Parihar, R. Sharma, K. S. Rathore and V. Parewa, Nanocatalysis in green organic synthesis, in Green Sustainable Process for Chemical and Environmental Engineering and Science, Elsevier, 2020, pp. 71-103; $(g)$ A. Dandia, P. Saini, R. Sharma and V. Parewa, Green organic synthesis by photochemical protocol, in Green Sustainable Process for Chemical and Environmental Engineering and Science, Elsevier, 2020, pp. 155-198; (h) 
A. Dandia, R. Sharma, A. Indora and V. Parewa, ChemistrySelect, 2018, 3, 8285-8290.

15 (a) A. Dandia, S. Parihar, P. Saini, K. S. Rathore and V. Parewa, Catal. Lett., 2019, 149, 3169-3175; (b) A. Dandia, D. K. Mahawar, R. Sharma, R. S. Badgoti, K. S. Rathore and V. Parewa, Appl. Organomet. Chem., 2019, 33, e5232; (c) A. Dandia, S. Bansal, R. Sharma, K. S. Rathore and V. Parewa, RSC Adv., 2018, 8, 30280-30288; (d) A. Dandia, A. Sharma, A. Indora, K. S. Rathore, A. Jain and V. Parewa, Mol. Catal., 2018, 459, 97-105.

16 A. Dandia, A. Sharma, V. Parewa, B. Kumawat, K. S. Rathore and A. Sharma, RSC Adv., 2015, 5, 91888-91902.

17 F. Atamny, J. Blocker, A. Dubotzky, H. Kurt, O. Timpe and G. Loose, Mol. Phys., 1992, 4, 851-886.

18 H. Yu, F. Peng, J. Tan, X. W. Hu, H. J. Wang and J. Yang, Angew. Chem., 2011, 123, 4064-4068.

19 (a) A. Corma, M. T. Navarro, L. Nemeth and M. Renz, Chem. Commun., 2001, 2190-2191; (b) J. Rivera-Utrilla and M. Sáchez-Polo, Appl. Catal., B, 2002, 39, 319-329.

20 (a) A. S. Mazur, M. A. Vovk and P. M. Tolstoy, Fullerenes, Nanotubes, Carbon Nanostruct., 2020, 28(3), 202-213; (b) M. A. Vieira, G. R. Gonçalves, D. F. Cipriano,
M. A. Schettino Jr, E. A. Silva Filho, A. G. Cunha and J. C. Freitas, Carbon, 2016, 98, 496-503.

$21 \mathrm{H}$. Li, F. Qin, Z. P. Yang, X. M. Cui, J. F. Wang and L. Z. Zhang, J. Am. Chem. Soc., 2017, 139, 3513-3521.

22 (a) A. Ding, Y. Zhang, Y. Chen, R. Rios, J. Hu and H. Guo, Tetrahedron Lett., 2019, 60, 660-663; (b) Y. L. Ren, X. Z. Tian, C. Dong, S. Zhao, J. Wang, M. Yan, X. Qi and G. Liu, Catal. Commun., 2013, 32, 15-17; (c) R. Gujjarappa, N. Vodnala, A. Garg, C. K. Hazra, S. Gupta and C. C. Malakar, ChemistrySelect, 2020, 5, 2419-2423.

23 (a) I. B. Seiple, S. Shun, R. A. Rodriguez, R. Gianatassio, Y. Fujiwara, A. L. Sobel and P. S. Baran, J. Am. Chem. Soc., 2010, 132, 13194-13196; (b) N. R. Patel and R. A. Flowers, J. Am. Chem. Soc., 2013, 135, 4672-4675; (c) A. S. Demir, O. Reis and M. Emrullahoglu, J. Org. Chem., 2003, 68, 578580; (d) G. Yan, M. Yang and X. Wu, Org. Biomol. Chem., 2013, 11, 7999-8008.

24 (a) G. A. Molander and L. N. Cavalcanti, J. Org. Chem., 2011, 76, 7195-7203; (b) R. W. Alder, J. Chem. Soc., Chem. Commun., 1980, 24, 1184-1186; (c) S. Hashimoto, I. Kurimoto, Y. Fujii and R. Noyori, J. Am. Chem. Soc., 1985, 107, 1427-1429. 